\title{
Mn-ion-enhanced red spectral emission from yttrium aluminum garnet doped cerium phosphor
}

\author{
ZHAO YinSheng ${ }^{1}$, ZHONG JiaSong ${ }^{1}$, XIANG WeiDong ${ }^{1 *}$, HUA Wei $^{2}$, YANG HaiLong ${ }^{1}$, \\ WANG Jing ${ }^{1}$, CAI Wen ${ }^{1}$, DONG YongJun ${ }^{3} \&$ SHAO MingGuo $^{2}$ \\ ${ }^{1}$ School of Materials Science and Engineering, Tongji University, Shanghai 201804, China; \\ ${ }^{2}$ College of Chemistry and Materials Engineering, Wenzhou University, Wenzhou 325035, China; \\ ${ }^{3}$ Shanghai Institute of Optics and Fine Mechanics, Chinese Academy of Sciences, Shanghai 201800, China
}

Received February 22, 2011; accepted June 30, 2011

\begin{abstract}
Mn ions were co-doped in yttrium aluminum garnet doped cerium (YAG:Ce) phosphors as a co-activator and host lattice element using the co-precipitation method. These ions broadened the emission spectra of the pure YAG:Ce phosphor, which is caused by the ${ }^{2} \mathrm{E}-{ }^{4} \mathrm{~A}_{2},{ }^{5} \mathrm{E}-{ }^{5} \mathrm{~T}_{2}$ or ${ }^{1} \mathrm{~T}_{2}-{ }^{5} \mathrm{~T}_{2}$ transition. From our X-ray diffraction results, we observed that $\mathrm{Ce}^{3+}(1.032 \AA)$ was substituted at the $\mathrm{Y}^{3+}(0.900 \AA)$ site, and $\mathrm{Mn}^{4+}(0.538 \AA)$ and $\mathrm{Mn}^{3+}(0.67 \AA)$ were substituted at the $\mathrm{Al}^{3+}(0.535 \AA)$ site. The chromaticity color co-ordinates of YAG:Ce $\mathrm{C}_{0.06}$ is $(0.203,0.167)$, and the indices of YAG:Ce $\mathrm{Ce}_{0.06}, \mathrm{Mn}_{0.04}$ and YAG:Ce $\mathrm{C}_{0.06}, \mathrm{Mn}_{0.08}$ are $(0.249,0.181)$ and $(0.233,0.194)$, respectively. The manganese co-doped yttrium aluminum garnet doped cerium blended with the YAG:Ce phosphor showed improved white light emission.
\end{abstract}

phosphor, LED, manganese, YAG:Ce

Citation: Zhao Y S, Zhong J S, Xiang W D, et al. Mn-ion-enhanced red spectral emission from yttrium aluminum garnet doped cerium phosphor. Chinese Sci Bull, 2011, 56: 3866-3870, doi: 10.1007/s11434-011-4780-9

Ce-doped yttrium aluminum garnet (YAG) $\mathrm{Y}_{3} \mathrm{~A}_{1}{ }_{5} \mathrm{O}_{12}$ has been widely used in solid-state laser materials and phosphors $[1,2]$. However, YAG:Ce is also a promising candidate for use in cathode-ray tubes (CRTs), field emission displays (FEDs), vacuum fluorescent displays (VFDs), and white light-emitting diodes (WLEDs) [3-5]. In contrast to single Ce doped YAG phosphor, which can convert blue light to yellowish-green light [2], some co-doped YAG:Ce phosphors have been studied that increase the emission efficiency and broaden luminosity spectra. The materials use rare earth elements, such as $\mathrm{Pr}^{3+}, \mathrm{Sm}^{3+}$, or $\mathrm{Tb}^{3+}$ ions [6-9]. However, few studies examine YAG:Ce phosphors co-doped with transition elements.

The ions of manganese, which is a transition element with various common ionization states, are well-known activators used in YAG mainly to produce tunable solid-state laser media [10]. The different charges of the Mn ions (2+,

*Corresponding author (email: xiangweidong001@126.com)
$3+$, and 4+) have different luminescence properties, depending on the charge state of the co-dopants and content of the growth environment. Similar to the ${ }^{6} \mathrm{~A}_{1}-{ }^{4} \mathrm{~A}_{1}$ and ${ }^{6} \mathrm{~A}_{1}-{ }^{4} \mathrm{~T}_{2}$ transitions, $\mathrm{Mn}^{2+}$ can be excited between 400 and $520 \mathrm{~nm}$ [11]. The luminescence spectrum of $\mathrm{Mn}^{4+}$ ions can be excited in the band that peaks between 460 and $480 \mathrm{~nm}$, which is caused by the ${ }^{2} \mathrm{E}-{ }^{4} \mathrm{~A}_{2}$ transitions [12]. However, the luminescence of $\mathrm{Mn}^{3+}$ in the octahedral sites of $\mathrm{Al}$ - in the garnet lattice usually results in intensive luminescence caused by the ${ }^{5} \mathrm{E}^{-5} \mathrm{~T}_{2}$ or ${ }^{1} \mathrm{~T}_{2}-{ }^{5} \mathrm{~T}_{2}$ transition in the orange-red spectral range [13,14]. Although the co-doped YAG:Ce phosphor has been previously studied, to the best of our knowledge few studies of the luminescence in YAG: Ce,Mn phosphors have been published.

We attempted to develop YAG:Ce,Mn phosphors excitable via blue light for application in white light LEDs. YAG phosphor powders are usually produced via solid state reactions [15], the sol-gel method [16], the glycothermal method [17], spray pyrolysis [18], or the co-precipitation method 
[19]. In this experiment, YAG:Ce and YAG:Ce,Mn phosphors were synthesized via a co-precipitation method: appropriate amounts of $\mathrm{MnCl}_{2}, \mathrm{Ce}\left(\mathrm{NO}_{3}\right)_{3}, \mathrm{Y}\left(\mathrm{NO}_{3}\right)_{3}$, and $\mathrm{Al}\left(\mathrm{NO}_{3}\right)_{3}$ solutions were mixed. These solutions were prepared by dissolving the corresponding nitrate salts in distilled water or dissolving them in $\mathrm{HNO}_{3}$ and $\mathrm{HCl}$.

\section{Experiment}

\subsection{Materials}

$\mathrm{Y}_{2} \mathrm{O}_{3}$ (99.99\%, Changchun Hai Puri Co. Ltd., Changchun, China) and $\mathrm{Ce}\left(\mathrm{NO}_{3}\right)_{3} \cdot 6 \mathrm{H}_{2} \mathrm{O}$ (A.R., Shanghai Zhanyun Chemical Co. Ltd., Shanghai, China) were used as rare earth sources. $\mathrm{Al}\left(\mathrm{NO}_{3}\right)_{3} \cdot 9 \mathrm{H}_{2} \mathrm{O}$ (A.R., Shanghai Zhanyun Chemical Co. Ltd., Shanghai, China), which was used as the source of $\mathrm{Al}$, and $\mathrm{MnO}_{2}(98 \%$, Sino-Chemical Reagent Company, Shanghai, China) were used as the transition element sources for YAG:Ce,Mn. The synthesis method is as follows.

High purity $\mathrm{Y}_{2} \mathrm{O}_{3}$ and $\mathrm{MnO}_{2}$ were dissolved in $\mathrm{HNO}_{3}$ and $\mathrm{HCl}$, respectively, through stirring and heating. Cerium and aluminum nitrate solutions were prepared by dissolving $\mathrm{Ce}\left(\mathrm{NO}_{3}\right)_{3} \cdot 6 \mathrm{H}_{2} \mathrm{O}$ and $\mathrm{Al}\left(\mathrm{NO}_{3}\right)_{3} \cdot 9 \mathrm{H}_{2} \mathrm{O}$ in distilled water. The multi-cation solution was prepared using the stoichiometric proportion: $\mathrm{Y}_{3-x} \mathrm{Ce}_{x} \mathrm{Al}_{5} \mathrm{O}_{12}(x=0.02,0.04,0.06,0.08$, $0.10)$ and $\mathrm{Y}_{2.94} \mathrm{Ce}_{0.06} \mathrm{Al}_{5-y} \mathrm{Mn}_{y} \mathrm{O}_{12}(y=0.02,0.04,0.06,0.08)$. The total cation concentration was $0.16 \mathrm{~mol} / \mathrm{L}$.

The concentration of ammonium hydrogen carbonate (AHC), which was used as the precipitant solution dissolved in the distilled water, was $2 \mathrm{~mol} / \mathrm{L}$.

\subsection{Powder synthesis}

Precursors were produced by dripping $300 \mathrm{~mL}$ of the precipitant solution (AHC) into $300 \mathrm{~mL}$ of the multi-cation solution at $2 \mathrm{~mL} / \mathrm{min}$ under magnetic stirring at room temperature. The solution was stirred for another $60 \mathrm{~min}$ after all of the $\mathrm{AHC}$ was added. After aging for $4 \mathrm{~h}$ at $25^{\circ} \mathrm{C}$, the resulting suspensions were filtered and washed three times with distilled water, rinsed three times with ethyl alcohol, and dried at $110^{\circ} \mathrm{C}$ for $10 \mathrm{~h}$. Then, the precursors were sintered at $1200^{\circ} \mathrm{C}$ for $2 \mathrm{~h}$ in air.

\subsection{Powder characterization}

X-ray powder diffraction (XRD) was carried out on a Bruker D8 Advance diffract meter (Germany; $40 \mathrm{kV}, 40$ $\mathrm{mA})$ using $\mathrm{Cu} \mathrm{K} \alpha$ radiation $(\lambda=0.15406 \mathrm{~nm})$ at a scanning rate of $0.02 \%$. Field-emission scanning electron microscope (FE-SEM) images were taken with a JEOL instrument (JEOL-6700F, Japan) at an accelerating voltage of $10 \mathrm{kV}$. The excitation and emission spectra were obtained with a FluoroMax-4 luminescence spectrometer (Horiba Jobin Yvon Co. Ltd., France) and the photoelectricity tests were performed using a PMS-50 (Everfine Co., Shanghai, China). All the measurements were carried out at room temperature.

\section{Results and discussion}

The Ce-doped YAG phosphors ions were prepared at $1200^{\circ} \mathrm{C}$ for $2 \mathrm{~h}$. Figure 1 shows the emission (Figure 1(a)) and excitation (Figure 1(b)) spectra of the YAG:Ce phosphors. As the concentration of Ce ions increased, the excitation and emission intensities showed similar changes. The intensities of emission and excitation were especially similar for the YAG:Ce $\mathrm{C}_{0.06}, \mathrm{YAG}: \mathrm{Ce}_{0.08}$, and YAG:Ce $\mathrm{C}_{0.1}$ phosphors. Although the concentrations of Ce ions are different, the emission spectra have the same peaks at $528 \mathrm{~nm}$ in each case, originating from the ${ }^{2} \mathrm{~T}_{2 \mathrm{~g}}(5 \mathrm{~d})-{ }^{2} \mathrm{~F}_{7 / 2},{ }^{2} \mathrm{~F}_{5 / 2}$ (4f) transition of the $\mathrm{Ce}^{3+}$ ions, which was excited at a fixed excitation wavelength of $460 \mathrm{~nm}$. The maximum emission intensity was demonstrated via the YAG: $\mathrm{Ce}_{0.06}$ phosphor. This is shown in Figure 1(a). The emission intensities of YAG: $\mathrm{Ce}_{0.08}$ and YAG:Ce $\mathrm{C}_{0.1}$ were not as high as that of YAG: $\mathrm{Ce}_{0.06}$ because of concentration quenching [20]. Figure 1(b)
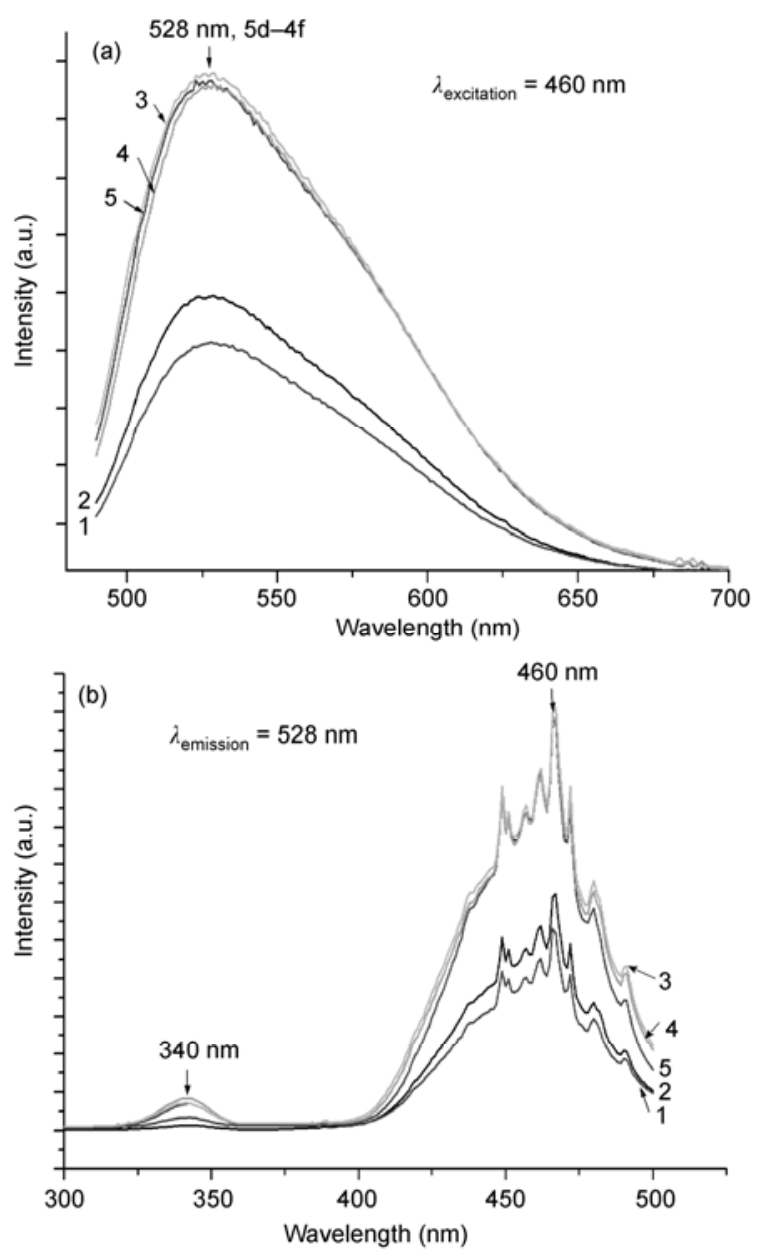

Figure 1 Emission (a) and excitation (b) spectra of YAG:Ce ${ }_{0.02}(1), \mathrm{YAG}$ $\mathrm{Ce}_{0.04}$ (2), YAG:Ce $\mathrm{Ce}_{0.06}(3), \mathrm{YAG}: \mathrm{Ce}_{0.08}(4)$, and YAG:Ce $\mathrm{C}_{0.1}$ (5) phosphors. 
shows the excitation spectra for excitation at $528 \mathrm{~nm}$. In these spectra, the excitation peaks at 340 and $460 \mathrm{~nm}$ can be seen.

Figure 1(a) shows that the emission of YAG:Ce $\mathrm{Ce}_{0.06}$ was more intense than that of the other YAG: $\mathrm{Ce}_{x}(x=0.02,0.04$, $0.08,0.10)$ phosphors. Therefore, the Mn ions were doped into YAG: $\mathrm{Ce}_{0.06}$. Figure 2 shows the X-ray powder diffraction patterns for the YAG:Ce $\mathrm{Ce}_{0.06}$ and $\mathrm{YAG}: \mathrm{Ce}_{0.06}, \mathrm{Mn}_{y}$ $(y=0.02,0.04,0.06,0.08)$ phosphors. All the diffraction peaks were indexed based on the pure YAG phase (Figure 2, JCPDS file 33-0040), with no impurity peaks. The phase of the YAG: $\mathrm{Ce}_{0.06}, \mathrm{Mn}_{y}(y=0.02,0.04,0.06,0.08)$ phosphors was the same as that of YAG: $\mathrm{Ce}_{0.06}$, which indicates that the refined lattice parameters did not undergo significant changes following Mn-ion co-doping. In addition, the patterns of YAG: $\mathrm{Ce}_{0.06}, \mathrm{Mn}_{y}(y=0.02,0.04,0.06,0.08$ ) (Figure 2(b)-(e)) showed clear shifts to lower $2 \theta$ angles, compared with the peaks of YAG:Ce $\mathrm{C}_{0.06}$ (Figure 2(a)). Previous studies suggest that the shift was caused by substituting larger dopant ions at the sites [12]. Because the phosphor samples were prepared in air, the co-doped $\mathrm{Mn}$ ions had mainly +3 and +4 charges [11]. Based on the radii of $\mathrm{Mn}^{4+}(0.538 \AA)$ and $\mathrm{Mn}^{3+}(0.645 \AA)$, and compared with those of $\mathrm{Y}^{3+}(0.900$ $\AA)$ and $\mathrm{Al}^{3+}(0.535 \AA)$, we can prove that Al-sites would be substituted mainly by the $\mathrm{Mn}^{4+}$ and $\mathrm{Mn}^{3+}$ ions, which can explain why there is a shift to a lower $2 \theta$ angle.

The sizes of YAG:Ce $e_{0.06}$ (Figure 3(a)) and YAG:Ce $\mathrm{C}_{0.06}$, $\mathrm{Mn}_{0.08}$ (Figure 3(b) and (c)) are shown in Figure 3. The morphology and microstructure of the samples were examined using FE-SEM. Figure 3(a) and (b) shows low-magnification $(10000 \times)$ SEM images that present a full view of the samples. The size distribution broadened to $200-500 \mathrm{~nm}$, with the increase of the $\mathrm{Mn}$ ion concentration. The material also became spherical with the addition of the Mn ions. All of the microspheres have similar sizes and morphologies. This suggests that the structure may be superior for some applications. Figure 3(c) shows a higher magnification

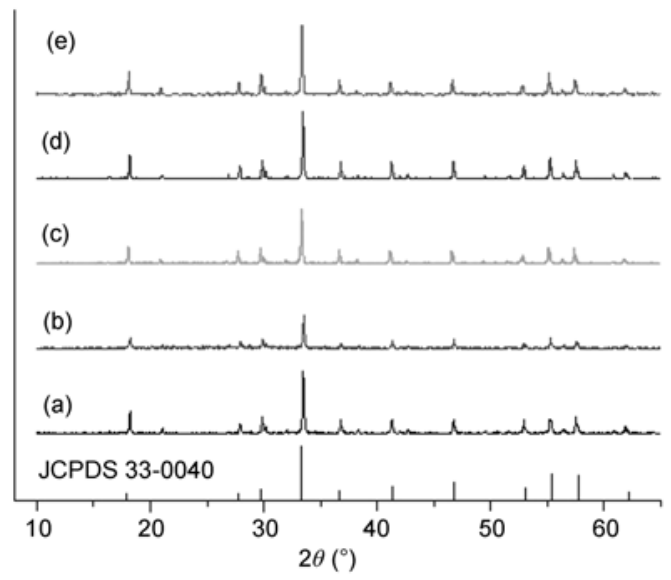

Figure 2 Powder X-ray diffraction patterns of (a) YAG:Ce $\mathrm{Ce}_{0.06}$, (b) YAG: $\mathrm{Ce}_{0.06}, \mathrm{Mn}_{0.02}$, (c) YAG:Ce $\mathrm{Ce}_{0.06}, \mathrm{Mn}_{0.04}$, (d) YAG:Ce $\mathrm{Ce}_{0.06}, \mathrm{Mn}_{0.06}$, and (e) YAG: $\mathrm{Ce}_{0.06}, \mathrm{Mn}_{0.08}$ phosphor.
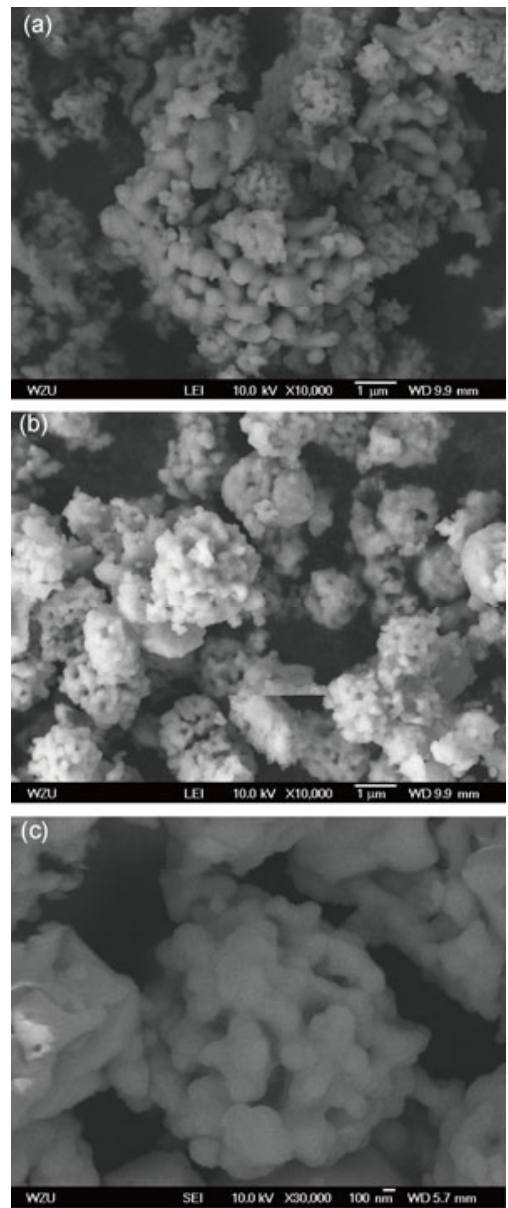

Figure 3 SEM of (a) YAG:Ce $e_{0.06}$ and (b), (c) YAG:Ce $\mathrm{Ce}_{0.06}, \mathrm{Mn}_{0.08}$ phosphor.

(30000×) SEM image of the YAG:Ce $\mathrm{Ce}_{0.06}, \mathrm{Mn}_{0.08}$.

Co-doped YAG:Ce $\mathrm{C}_{0.06}$ phosphors with various $\mathrm{Mn}$ concentrations were excited at 390 and $460 \mathrm{~nm}$. The excitation at $390 \mathrm{~nm}$ occurs only for the $\mathrm{Mn}^{3+}$ ions, in contrast to the excitation wavelengths of $\mathrm{Mn}^{2+}$ and $\mathrm{Mn}^{4+}$ ions [21]. By contrast, excitation at $460 \mathrm{~nm}$ only occurs for $\mathrm{Mn}^{4+}$ [12] and $\mathrm{Ce}^{3+}$. We observed from the emission spectra corresponding to 460-nm excitation (Figure 4(a)) that YAG:Ce has a broad band emission with a peak at $538 \mathrm{~nm}$ and sharp emission peaks at 504, 625, and $691 \mathrm{~nm}$. Using the emission spectrum of YAG: $\mathrm{Ce}_{0.06}$ (Figure 1(a)) as a reference, the addition of $\mathrm{Mn}$ ions at the $\mathrm{Al}$ site resulted in a significant red shift with the emission maxima shifting from 528 to $538 \mathrm{~nm}$ because of the ${ }^{2} \mathrm{E}-{ }^{4} \mathrm{~A}_{2},{ }^{5} \mathrm{E}-{ }^{5} \mathrm{~T}_{2}$, and ${ }^{1} \mathrm{~T}_{2}-{ }^{5} \mathrm{~T}_{2}$ transitions [12], and also for the peaks at 504, 625, and $691 \mathrm{~nm}$. With increasing $\mathrm{Mn}$-ion concentration, the emission intensity of the YAG:Ce,Mn generally increased. This is shown in Figure 4(a). Figure 4(b) shows the excitation spectra of YAG:Ce $\mathrm{C}_{0.06}$, $\mathrm{Mn}_{0.06}$ detected at 504, 538, 625, and $691 \mathrm{~nm}$. The range of the excitation spectra is from 320 to $490 \mathrm{~nm}$, which indicates that the YAG:Ce,Mn phosphors can also be excited using blue light. Figure 5 shows the emission spectra of YAG: $\mathrm{Ce}_{0.06}$ and YAG:Ce $\mathrm{Ce}_{0.06}, \mathrm{Mn}_{0.08}$. From the spectra, we 

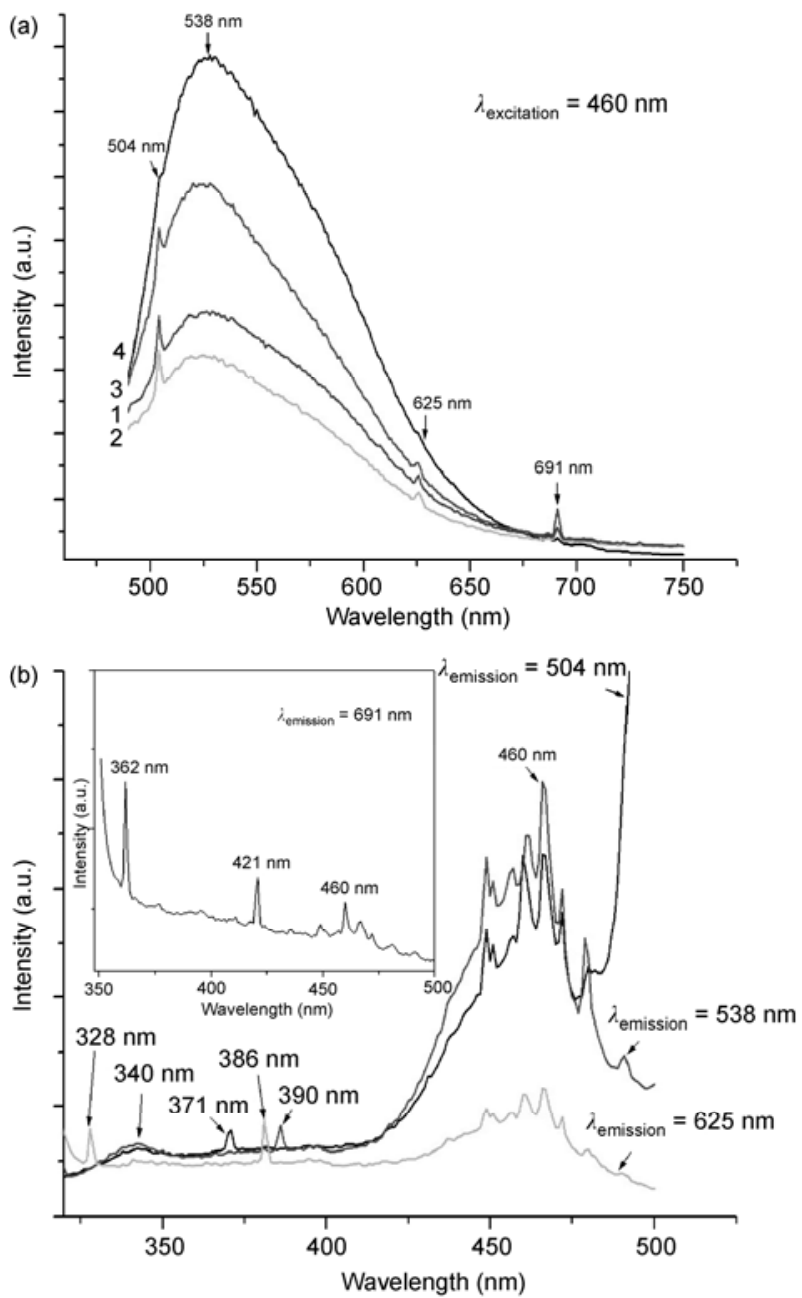

Figure 4 (a) Emission spectra of YAG:Ce,Mn for excitation at $460 \mathrm{~nm}$. 1, YAG: $\mathrm{Ce}_{0.06}, \mathrm{Mn}_{0.02} ; 2$, YAG:Ce $\mathrm{Ce}_{0.06}, \mathrm{Mn}_{0.04} ; 3, \mathrm{YAG}: \mathrm{Ce}_{0.06}, \mathrm{Mn}_{0.06} ;$ and 4 , YAG: $\mathrm{Ce}_{0.06}, \mathrm{Mn}_{0.08}$ phosphor. (b) Excitation spectra of YAG:Ce $\mathrm{Ce}_{0.06}, \mathrm{Mn}_{0.06}$ detected at 504, 538, 625, $691 \mathrm{~nm}$.

can see that the full width at half maximum (FWHM) of YAG:Ce $e_{0.06}$ is $92 \mathrm{~nm}$ and the FWHM of YAG:Ce $\mathrm{Ce}_{0.06}, \mathrm{Mn}_{0.08}$ is $103 \mathrm{~nm}$. When excited with near-UV light at $390 \mathrm{~nm}$ (Figure 6(a)), Mn-codoped YAG:Ce phosphors showed the characteristic $\mathrm{Mn}^{3+}$ peaks at 531,641 , and $744 \mathrm{~nm}$, which cannot be excited in pure YAG:Ce. The excitation spectra of YAG:Ce $\mathrm{Ce}_{0.06}, \mathrm{Mn}_{0.06}$ are shown in Figure 6(b). The detected emission wavelengths of 531, 641, and $744 \mathrm{~nm}$ represent the excitation peaks from 336 to $490 \mathrm{~nm}$. Generally, increasing the concentration of $\mathrm{Mn}$ ions enhanced the bandwidth of the emission spectra of the YAG:Ce,Mn phosphors.

Table 1 lists the photoelectricity parameters for YAG: $\mathrm{Ce}_{0.06}, \mathrm{Mn}_{y}(y=0,0.02,0.04,0.06,0.08)$. The chromaticity color co-ordinates shifted toward the optimum white light emission region for the YAG:Ce,Mn phosphors compared with that of YAG:Ce. The CIE chromaticity comprises two color co-ordinates, $x$ and $y$, which specify the point on the chromaticity diagram in Figure 7. The CIE color co-ordinates of YAG:Ce and YAG:Ce,Mn phosphors, which were excited

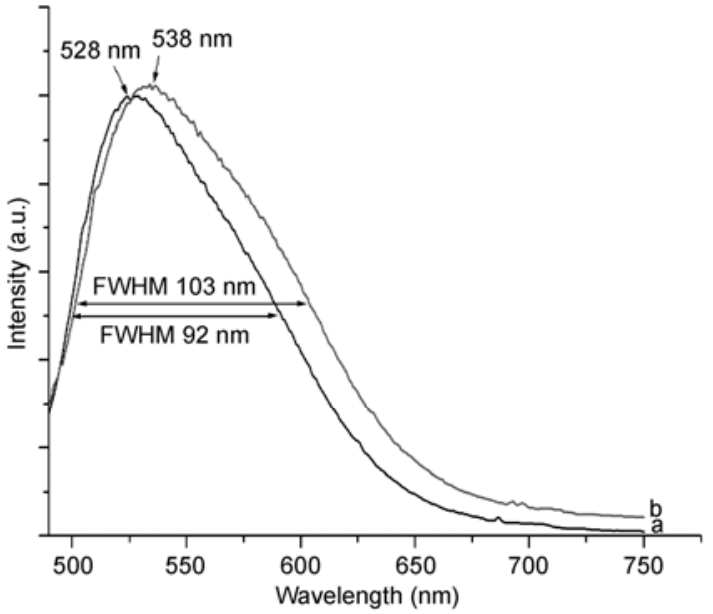

Figure 5 FWHM of (a) YAG:Ce $0_{0.06}$ and (b) YAG:Ce $e_{0.06}, \mathrm{Mn}_{0.08}$.
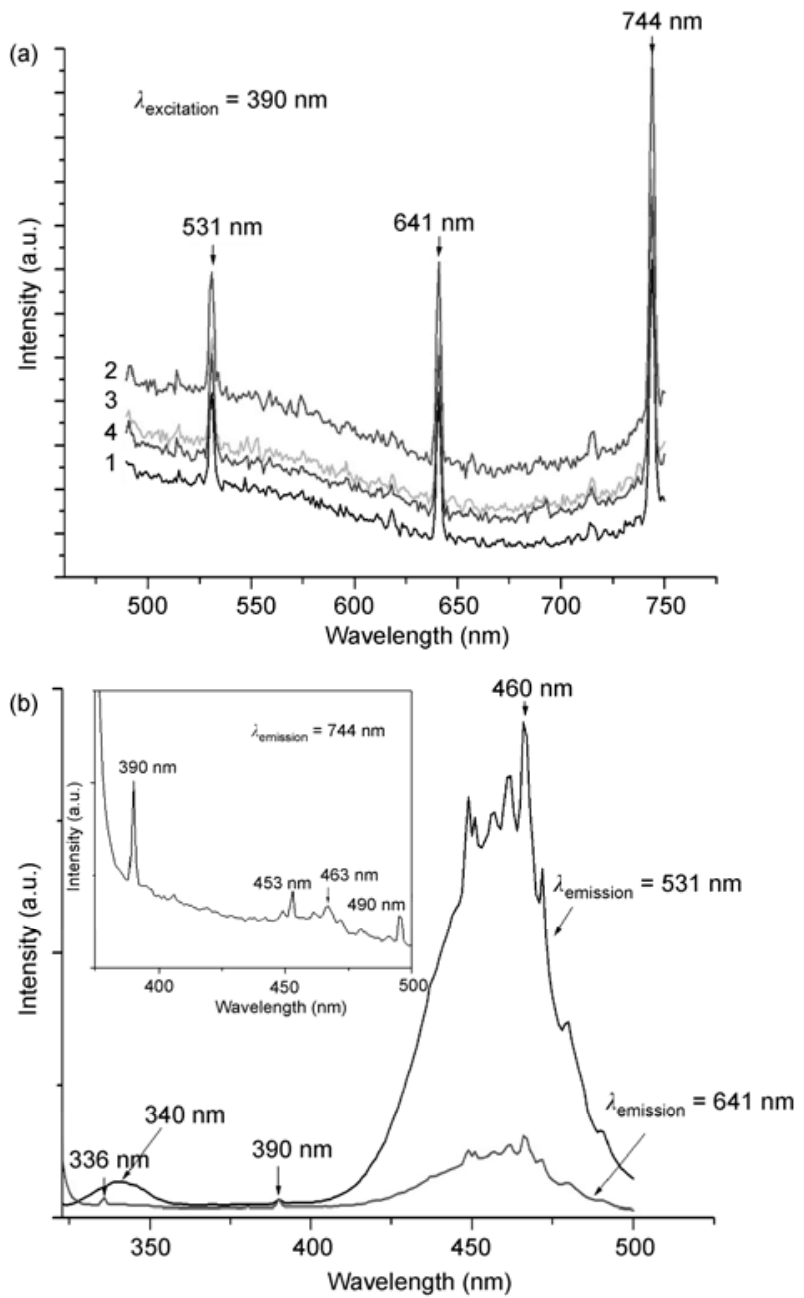

Figure 6 (a) Emission spectra of YAG:Ce,Mn for excitation at $390 \mathrm{~nm}$. 1, YAG: $\mathrm{Ce}_{0.06}, \mathrm{Mn}_{0.02} ; 2, \mathrm{YAG}: \mathrm{Ce}_{0.06}, \mathrm{Mn}_{0.04} ; 3, \mathrm{YAG}: \mathrm{Ce}_{0.06}, \mathrm{Mn}_{0.06}$; and 4, YAG:Ce $\mathrm{Ce}_{0.06}, \mathrm{Mn}_{0.08}$ phosphor. (b) Excitation spectra of YAG: $\mathrm{Ce}_{0.06}, \mathrm{Mn}_{0.06}$, detected at 531, 641 and $744 \mathrm{~nm}$.

using a blue LED, are shown in Figure 7. When the YAG:Ce ${ }_{0.06}$ phosphor with a co-ordinate of $(0.203,0.167)$ was co-doped with Mn ions, the color co-ordinate of the 
Table 1 Photoelectric parameters of YAG:Ce ${ }_{0.06}, \mathrm{Mn}_{y}$ phosphor

\begin{tabular}{ccc}
\hline Concentration of $\mathrm{Mn}(\mathrm{mol} / \mathrm{L})$ & Color co-ordinate $x$ & Color co-ordinate $y$ \\
\hline 0 & 0.203 & 0.167 \\
0.02 & 0.207 & 0.157 \\
0.04 & 0.249 & 0.181 \\
0.06 & 0.22 & 0.173 \\
0.08 & 0.233 & 0.194 \\
\hline
\end{tabular}

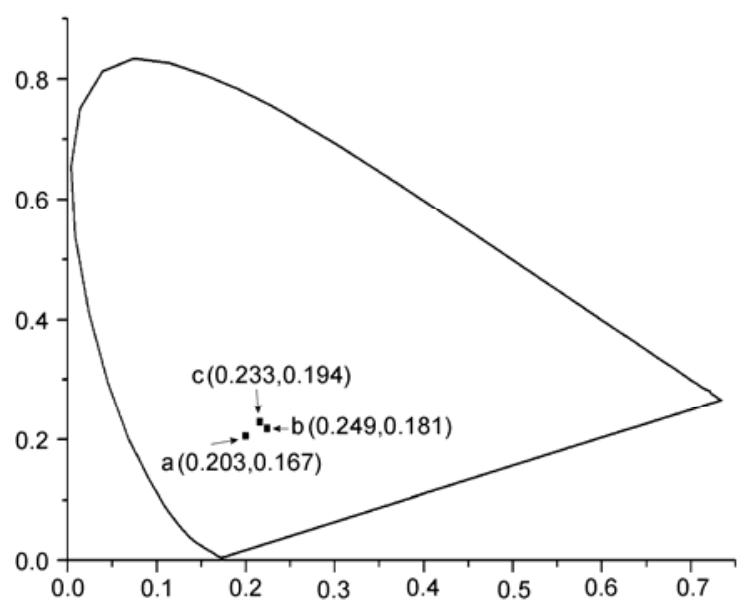

Figure 7 CIE color co-ordinates for YAG:Ce ${ }_{0.06}$ (a), YAG:Ce $\mathrm{Ce}_{0.06}, \mathrm{Mn}_{0.04}$ (b), and YAG:Ce $\mathrm{Ce}_{0.06}, \mathrm{Mn}_{0.08}$ (c) phosphors.

emitted light was shifted to $(0.249,0.181)$ for the YAG: $\mathrm{Ce}_{0.06}, \mathrm{Mn}_{0.04}$ and $(0.233,0.194)$ for the YAG:Ce $\mathrm{Ce}_{0.06}$, $\mathrm{Mn}_{0.08}$, which are closer to the value for standard white light. This shows that by using a fixed excitation light $(460 \mathrm{~nm})$, bright white light with different color co-ordinates can be obtained using YAG:Ce,Mn phosphors.

\section{Conclusion}

The properties of YAG:Ce phosphors were altered through the co-doping of Mn ions. Compared with that of YAG:Ce phosphor, Mn co-doped YAG:Ce phosphors red-shifted about $10 \mathrm{~nm}$ because of the ${ }^{2} \mathrm{E}-{ }^{4} \mathrm{~A}_{2},{ }^{5} \mathrm{E}-{ }^{5} \mathrm{~T}_{2}$, and ${ }^{1} \mathrm{~T}_{2}-{ }^{5} \mathrm{~T}_{2}$ transitions of the Mnions. We found that as the concentration of the Mn ions increased, the emission intensity also increased. The CIE color co-ordinates for YAG:Ce $\mathrm{C}_{0.06}$, $\mathrm{Mn}_{0.04}$ and YAG: $\mathrm{Ce}_{0.06}, \mathrm{Mn}_{0.08}$ are $(0.249,0.181)$ and $(0.233$, $0.194)$, respectively. This is in contrast to the CIE color co-ordinates for YAG: $\mathrm{Ce}_{0.06}(0.203,0.167)$. Therefore, cerium-manganese-co-doped yttrium aluminum garnet blended with cerium-doped yttrium aluminum garnet phosphor has an improved white light emission spectrum, which is promising for use in white LEDs.
This work was supported by the National Natural Science Foundation of China (60708021), Science and Technology Program of Wenzhou (G20090082), Important Basic Research Program of Shanghai (09JC1414900), Optics Science and Technology Foundation of Shanghai (09DZ1142002 and 10DZ1140400), Key Foundation of Zhejiang Province Natural Science Foundation (Z4110347), Foundation of Zhejiang Province Nano Technology Innovation Team (2009R50010).

1 Hassanzadeh-Tabrizi S A, Taheri-Nassaj E, Sarpoolaky H. Synthesis of an alumina-YAG nanopowder via sol-gel method. J Alloy Compd, 2008, 456: 282-285

2 Kottaisamy M, Thiyagarajan $\mathrm{P}$, Mishra J, et al. Color tuning of $\mathrm{Y}_{3} \mathrm{Al}_{5} \mathrm{O}_{12}$ :Ce phosphor and their blend for white LEDs. Mater Res Bull, 2008, 43: 1657-1663

3 Zhang K, Liu H Z, Wu Y T, et al. Co-precipitation synthesis and luminescence behavior of Ce-doped yttrium aluminum garnet (YAG:Ce) phosphor: The effect of precipitant. J Alloy Compd, 2008, 453: $265-270$

4 Zhang N, Wang D J, Li L. YAG:Ce phosphors for WLED via nano-pesudoboehmite sol-gel route. J Rare Earth, 2006, 24: 294-297

5 Wu Z G, Zhang X D, He W. Solvothermal synthesis of spherical YAG powders via different precipitants. J Alloy Compd, 2009, 472: 576-580

6 Yang H S, Kim Y S. Energy transfer-based spectral properties of Tb-, Pr-, or Sm-codoped YAG:Ce nanocrystalline phosphors. J Lumin, 2008, 128: 1570-1576

7 Zhou Y, Lin J, Yu M, et al. Synthesis-dependent luminescence properties of $\mathrm{Y}_{3} \mathrm{Al}_{5} \mathrm{O}_{12}: R e^{3+}(R e=\mathrm{Ce}, \mathrm{Sm}, \mathrm{Tb})$ phosphors. Mater Lett, 2002, 56: 628-636

8 Ho S J, Won B L, Dong C L, et al. Enhancement of red spectral emission intensity of $\mathrm{Y}_{3} \mathrm{Al}_{5} \mathrm{O}_{12}: \mathrm{Ce}^{3+}$ phosphor via Pr co-doping and Tb substitution for the application to white LEDs. J Lumin, 2007, 126: 371-377

9 Nakielska M, Kosko J, Sarnecki J, et al. Fluorescence properties in the visible of highly $\operatorname{Pr}^{3+}$ doped YAG planar waveguides. Opt Mater, 2008, 30: 759-762

10 Noginov M A, Loutts G B, Warren M. Spectroscopic studies of $\mathrm{Mn}^{3+}$ and $\mathrm{Mn}^{2+}$ ions in $\mathrm{YAlO}_{3}$. J Opt Soc Am B, 1999, 16: 475-483

11 Yu Z, Gorbenko V, Voznyak T, et al. Luminescence of $\mathrm{Mn}^{2+}$ ions in $\mathrm{Tb}_{3} \mathrm{Al}_{5} \mathrm{O}_{12}$ garnet. J Lumin, 2010, 130: 380-386

12 Donegan J F, Glynn T J, Imbusch G F. Luminescence and fluorescence line narrowing studies of $\mathrm{Y}_{3} \mathrm{Al}_{5} \mathrm{O}_{12}: \mathrm{Mn}^{4+}$. J Lumin, 1986, 36: 93-100

13 Stefan K, Simone H, Stephan $\mathrm{H}$, et al. $\mathrm{Mn}^{3+}$ fundamental spectroscopy and excited state absorption. Phys Solid State, 1998, 8: 206-209

14 Stefan K, Simone H, Stephan H, et al. Emission of octahedrally coordinated $\mathrm{Mn}^{3+}$ in garnets. Spectrochim Acta A, 1998, 54: 1741-1749

15 Stefan K, Simone H, Stephan H, et al. Optical transition in $\mathrm{Mn}^{3+}$ doped garnets. Phys Rev B, 1998, 57: 2203-2216

16 Kyung N K, Jung H K, Hee D P, et al. High luminance of new green emitting phosphor $\mathrm{Mg}_{2} \mathrm{SnO}_{4}: \mathrm{Mn}$. J Lumin, 2002, 99: 169-173

17 Kasuya R, Isobe T, Kuma H. Glycothermal synthesis and photoluminescence of YAG:Ce ${ }^{3+}$ nanophosphors. J Alloy Compd, 2006, 408-412: 820-823

18 Julien M, Tyrone J, Rita B, et al. Yttrium aluminum garnet nanopowders produced by liquid-feed flame spray pyrolysis of metallooraganic precursors. Chem Mater, 2004, 16: 822-831

19 Yuan F L, Ryu H J. Ce-doped YAG phosphor powders prepared by co-precipitation and heterogeneous precipitation. Mater Sci Eng B, 2004, 107: 14-18

20 Pan Y X, Wu M M, Su Q. Tailored photoluminescence of YAG:Ce phosphor through various methods. J Phys Chem Solids, 2004, 65: 845-850

21 Klaus P, Gunter H. Broad band fluorescence of transition metal doped garnets and tungstates. J Lumin, 1984, 31-32: 71-77

Open Access This article is distributed under the terms of the Creative Commons Attribution License which permits any use, distribution, and reproduction in any medium, provided the original author(s) and source are credited. 